\title{
REVIEW
}

\section{Slow drugs: slow progress? Use of slow acting antirheumatic drugs (SAARDs) in rheumatoid arthritis}

\author{
H A Capell, M Brzeski
}

Most rheumatologists use slow acting antirheumatic drugs (SAARDs) for treatment of rheumatoid arthritis (RA). This review looks at the perils and pitfalls associated with the introduction of new compounds in RA, the attempts that have been made to optimise available drugs, and the dilemmas of early and combination treatment. Finally, a brief mention is made of immunotherapy, which seems unlikely to provide a panacea in the near future.

Clearly, earlier terminology, such as 'remission inducing drugs', is not justified by the performance of these agents, and even 'disease modifying antirheumatic drug' implies a promise of a more fundamental effect on RA than is commonly produced. An acceptable alternative is 'second line drug', which encompasses the concept of another tier of treatment for generalised disease inadequately restrained by analgesia and non-steroidal antiinflammatory drugs. The implication of 'stepping up' the power of a drug treatment may also help patients to accept the risks of side effects of these drugs. The aim of complete disease remission, and the documented slow onset of action, sets these drugs apart from all other types of treatment in RA.

In this review the term slow acting antirheumatic drugs will be used to include antimalarial drugs, gold, penicillamine, sulphasalazine, and selected cytotoxic agents.

High drop out rates are a feature of these drugs, and as sustained intervention over many years is often necessary in the management of RA, rheumatologists may be forgiven for a feeling of frustration with the relative lack of progress in therapeutic options over the past 10 years. 'Designer drugs' have proved elusive in $R A$, and the difficulties that have been encountered in introducing new drugs in this category are in stark contrast with the successes elsewhere with $\mathrm{H}_{2}$ antagonists, prostaglandin analogues, $\boldsymbol{\beta}$ blockers, and angiotensin converting enzyme inhibitors.

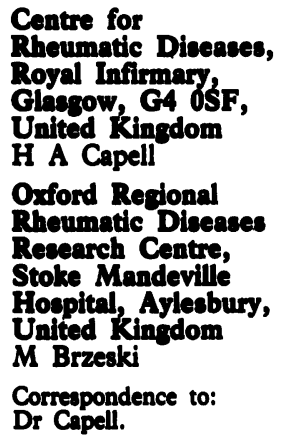

\section{Clinical benefits}

We know what benefits we can expect for our patients from these drugs. Few patients may satisfy American Rheumatism Association criteria for remission but, overall, 33-72\% will have a greater than $50 \%$ reduction in morning stiffness, number of tender joints, or equivalent clinical assessment of joint activity, and a further $33-50 \%$ will have some improvement in these indices. ${ }^{1}$ The erythrocyte sedimentation rate may fall by $50 \%$ or even to normal in up to half of patients, ${ }^{1}$ but worthwhile clinical response also occurs in patients with active synovitis who have a normal erythrocyte sedimentation rate or $\mathrm{C}$ reactive protein. ${ }^{2} \mathrm{Up}$ to three quarters may have side effects of varying severity, and up to half may stop sodium aurothiomalate by two years owing to side effects alone. ${ }^{3}$ Of those patients who do improve and experience no side effects, some will discontinue the drug owing to later loss of effect ('escape from control'). Compared with other SAARDs, injectable gold is generally regarded as producing fewest withdrawals for lack of effect (it is not clear how much this is due to the complete compliance obtained by intramuscular administration) and most withdrawals for side effects, ${ }^{4}$ though not all studies confirm this. ${ }^{5}$

\section{Evaluation of new compounds}

Overall, a large proportion of patients do not continue to receive any given drug for more than one year, ${ }^{3}$ so the search has continued for other, improved compounds. The difficulties of assessing disease activity and response to treatment are relevant to the search for new drugs but beyond the scope of this paper. Likewise, the possibly declining severity of RA during this century, and any effect of routine use of low dose steroids (hotly debated and currently being assessed), may carry implications for future management.

Assessment of new compounds in RA has long been bedevilled by the inability to elucidate mechanisms whereby these drugs exert their effect. While much remains to be explained about non-steroidal anti-inflammatory drugs, the arachidonic acid pathway and the effects of these agents on cyclo-oxygenase are well understood. By contrast, virtually all available second line agents for RA were discovered serendipitously and even the choice of the designer drug sulphasalazine was based on a false premise.

\section{Failures}

The track record of new compounds which have failed to reach fruition makes depressing reading: levamisole was effective but unacceptably toxic ${ }^{6}$; fenclofenac disappeared in infancy because of rashes despite early promise; ${ }^{7}$ clozic followed a similar fate; benoxaprofen led to 
photosensitivity and systemic upset ${ }^{8} ;$ primodone and timegadine ${ }^{9}$ did not draw breath; Seatone (green lipped mussel) ${ }^{10}$ ketotifen, ${ }^{11}$ and inosine pranobex ${ }^{12}$ proved entirely unhelpful; phenytoin $^{13}$ influenced laboratory indicators of disease activity more than clinical variables and therefore proved unhelpful; stanozolol ${ }^{14}$ led to early benefit outweighed by the unacceptable masculinising effects in patients, who are predominantly female; and rifampicin engendered a favourable preliminary report ${ }^{15}$ which was not substantiated. ${ }^{16}$ The vogue for antibiotic treatment has continued with evaluations of sulphonamides, ${ }^{17} 18$ minocycline, ${ }^{19}$ metronidazole ${ }^{20}$ and clotrimazole ${ }^{21}$ among othersso far without clearcut evidence of benefit.

\section{In limbo}

A preliminary favourable report ${ }^{22}$ of haloperidol has not been followed up-perhaps it should be. More promising reports of thiol containing drugs, such as captopril, ${ }^{23}$ have not resulted in widespread use in patients with RA, possibly because of unfamiliarity with the treatment and possibly because of the need to observe blood pressure closely as captopril is introduced. There might, however, be a case for selecting captopril in rheumatoid patients with congestive cardiac failure or hypertension in the expectation that effect on RA would be an additional bonus. If this tactic were tried, renal function would require close observation. Further, 10 out of 37 hypertensive patients taking very high doses of captopril developed antinuclear antibodies within six months, though clinical features of lupus were not seen. ${ }^{24}$ The role of thiol groups may be critical-the restoration of impaired redox homeostasis across cell membranes ${ }^{25}$ yet their presence in a compound is neither a guarantee of second line activity ${ }^{26}$ nor a prerequisite, as sulphasalazine demonstrates.

Cyclosporin A still has promise. A potent immunomodulator, it undoubtedly exerts an effect in RA at the high dose of $6-10 \mathrm{mg} / \mathrm{kg}$ daily, ${ }^{27}{ }^{28}$ but its usefulness in the long term is limited by fears of (irreversible?) nephrotoxicity. Lower doses (mean $3.8 \mathrm{mg} / \mathrm{kg}$ daily) are therapeutic but still toxic, and not all patients with cyclosporin induced nephropathy revert to baseline renal function after drug withdrawal. ${ }^{29}$ There are indirect suggestions that prostaglandin analogues (misoprostol) may ameliorate this problem if given in addition to cyclosporin. ${ }^{30}$ Although potentially convenient for those with peptic ulceration induced by non-steroidal antiinflammatory drugs, the data sheet would currently exclude women of child bearing years, unless using adequate contraception and diarrhoea might lead to withdrawal in a significant proportion of patients if full dose were used.

\section{Successes}

What has proved successful in the 1980s? The list is depressingly short, but nevertheless clinically valuable. Auranofin is in essence a reformulation of a known effective drug, sulphasalazine is a resurrection of a compound previously known to be effective, and methotrexate has moved sideways from dermatology.
Auranofin has a different, less toxic profile than injectable gold ${ }^{5}$ but takes longer to work than sulphasalazine ${ }^{31}$ or methotrexate, ${ }^{32}$ and if meta-analysis is to be believed ${ }^{4}$ is less effective than widely used alternatives. ${ }^{5}$ Its effect in psoriatic arthritis is 'modest' '33 $^{33}$ or negligible. ${ }^{34}$ Sulphasalazine has proved a useful addition to the rheumatologists' repertoire, ${ }^{35}$ and its beneficial effect in ankylosing spondylitis, ${ }^{36}$ psoriatic arthritis, ${ }^{37}$ and reactive arthritis ${ }^{38}$ makes it a more versatile drug than others in this category.

North American enthusiasm for methotrexate $^{39}$ is not mirrored to the same extent in Europe (and indeed the drug is decried by some in North America) ${ }^{40}$ though methotrexate is a useful addition in a field where long term survival with any one treatment is limited. More patients may ${ }^{3}$ or may not ${ }^{5}$ continue to receive methotrexate than alternative drugs, but there is no evidence that the effect on RA is any greater. The beneficial effect of methotrexate may occur within six weeks of starting treatment, however, and the option of parenteral therapy is useful where patient compliance is in question.

Long term toxicity risks with methotrexate still have to be clarified. The risk of neoplasia, if any, is unknown. Liver fibrosis developed in 14 of $27(52 \%)$ patients having routine serial biopsies over two to six years ${ }^{41}$ but was thought to be of no clinical significance (and it seems that routine liver biopsies are rarely required). Cirrhosis was not seen and increase of transaminases was rarely above twice normal. The authors concluded that liver biopsy is not indicated in the absence of previous alcohol abuse or liver disease, factors which we would regard as precluding a prescription of methotrexate in the first place. We do not permit concurrent alcohol use with methotrexate, but many studies have been far less restrictive. ${ }^{42}$

What has certainly been established is that there is no placebo response to SAARD treatment in patients with established $R A,{ }^{43}$ although some North American multicentre studies have shown less clear cut results in this respect. ${ }^{44}$ In the many patients with active RA who seek rheumatological help it is necessary to optimise treatment until a 'curative' drug is available. Possible ways of doing this are noted in the section below.

\section{Optimising use of available SAARDs}

Drop out rates from SAARD treatment are high more because of side effects than because of lack of effect or late loss of benefit. ${ }^{45}$ Relevant aspects here include attempts to predict 'point' toxicity and avoid cumulative toxicity. In addition, it is important to have a realistic idea of the expected effect of individual compounds and, wherever possible, to maximise their efficacy.

CAN WE REDUCE OR PREDICT TOXICITY? Apart from commonsense about the dose of cytotoxic and antimalarial drugs, several approaches have been tried. Desensitising 
patients with sulphasalazine induced rash is often effective. ${ }^{46}$ Withdrawals due to methotrexate toxicity may possibly be reduced though not abolished by concurrent folic acid supplementation, ${ }^{47}$ but such antidotes are unlikely to be found for other SAARDs. A recent study ${ }^{48}$ using pulsed methylprednisolone early during SAARD treatment found no benefit for toxicity or disease control.

Early studies about the effect of the order of SAARD administration failed to establish any convincing evidence that this was of importance. ${ }^{49}$ Many studies have looked at drug concentrations, in particular of gold $^{50}$ and sulphasalazine, ${ }^{51}$ and again these have proved disappointing. The effects of cigarette smoking ${ }^{52}$ and acetylator phenotype p3 $^{54}$ have not been shown to be useful predictors of toxicity. Impaired sulphoxidation (present in a greater percentage of rheumatoid patients than one might expect) is associated with an increased susceptibility to gold and penicillamine toxicity, ${ }^{55} 56$ though of little practical value at present. Similarly, HLA haplotyping is relatively unhelpful in a day to day sense, though it is possible to show that some side effectsfor example, proteinuria ${ }^{55}$ and precipitous thrombocytopenia ${ }^{57} 58$ during gold treatment, are related to the DR3 haplotype. For drug studies many pharmaceutical companies seek patients who have not previously received a slow acting drug, but there is no evidence that such patients are more or less likely to respond to a subsequent drug. Prediction of toxicity would only be of value if it were so certain that it would deter us from prescribing specific drugs to specific patients. None of the present techniques offers this. Toxicity prediction is unlikely to figure prominently in our routine practice, a conclusion also reached in a recent extensive review. ${ }^{59}$

\section{HOW TO MAXIMISE EFFICACY}

We suspect that much greater benefit might accrue from our available drugs by improving compliance $^{60}$ and the persistence with which they are used. This requires education of the patient to take the drug regularly and not to stop once improved or 'cured'. All side effects should be thoroughly assessed to consider causes not due to SAARDs, and patients may prefer to tolerate minor side effects if there has been a clinical improvement in their arthritis. Thrombocytopenia should be confirmed by a blood film to exclude clumping, an uncommon but wasteful reason for stopping a drug. We do not, after all, have an endless abundance of alternative SAARDs. Similarly, a careful increase in dose may pay dividends where response is suboptimal-for example, to sulphasalazine $40 \mathrm{mg} /$ day or gold $100 \mathrm{mg}$ weekly for five to six weeks.

\section{Radiological evaluation and treating early disease}

It is perhaps an irony that as new drugs become available there is an increasing tendency to study patients with early disease. Some patients thought to have early rheumatoid arthritis, however, may have a reactive arthritis to an infectious cause, and together with those who are seronegative might be expected to follow a relatively benign course. Early non-erosive disease is certainly not typical of the patient with RA whom rheumatologists are called upon to manage.

Proponents of delay rightly point out that as RA may remit or become less severe in many patients in the first year a large group of patients will be treated with SAARDs unnecessarily, with the allied cost in time, money, and exposure to potential side effects. It is not known whether SAARD treatment started within one or two months of disease onset, or before erosions have occurred, would confer any further benefit, or even arrest the process in its tracks. Conversely, the best chance of preserving good function and preventing disability, rather than responding to it, may lie in vigorous early treatment where there is a possibility of inducing remission before the disease has become entrenched. One risk of this approach is that as patients work their way through the SAARDs, cytotoxic drugs may be invoked earlier in the disease, and thus at an earlier age of the patient, an important point when considering possible late neoplasia. We need the ability reliably to identify, at an early stage, those patients with a poor prognosis. General features-for example, seropositivity, which predict more severe disease are not sufficiently specific to help in the individual case.

One important measure of disease activity is progression of erosions and joint space loss as seen on plain radiographs. Comparison of serial radiographs is fraught with difficulties, and most studies have concentrated on hands, though not all joints suffer radiological worsening concurrently or at the same rate. ${ }^{61}$ Others have been harshly critical of failure to document adequately radiological change. ${ }^{62}$ Cyclophosphamide is the only compound which has been shown to heal erosions, ${ }^{63}$ but most rheumatologists hesitate to use this drug early in the disease.

A recent study in early RA (mean disease duration 13.4 months $)^{64}$ showed significantly less erosions had developed with sulphasalazine than with hydroxychloroquine at one year. Although new erosions continued to develop over the next two years, the subsequent changes in radiographic scores were not significant, suggesting a marked deceleration in erosive disease. $^{65}$ Similar results with sulphasalazine were seen in a two year study of patients with longer disease duration. ${ }^{66} \mathrm{~A}$ two year, double blind, placebo controlled study of auranofin in early RA (median disease duration one year) ${ }^{67}$ also showed that auranofin could retard radiological progression in hands, wrists, and feet compared with placebo; despite this, a marked deterioration in Larsen index occurred in both groups. Other studies have shown that subgroups of patients with initially mild disease or responding well to SAARDs (meaning a fall of erythrocyte sedimentation rate to $<20 \mathrm{~mm} / \mathrm{h}$ or of articular index to $<5$ ) also had significant slowing of the radiological rate of progression. ${ }^{68}$ 
It seems likely, then, that some drugs may slow development of erosions. All this hints tantalisingly that SAARD treatment, if started early or pursued vigorously enough, might be beneficial to long term anatomical, and hence functional, preservation. Despite these relatively favourable early results there are no available long term studies to demonstrate that function over prolonged periods is enhanced or that the development of erosive disease will be similarly favourably influenced. Nor are there reliable data to suggest that early treatment brings about substantially more remissions. The verdict at present must remain 'not proven'.

\section{Combination therapy}

The success of combination chemotherapy for oncologists and haematologists has encouraged similar work in RA. Rheumatologists, however, are disadvantaged by ignorance of the mode of action of their drugs. This precludes any logical formulation of drug combinations, just as it precludes defining the appropriate sequence, if any, in which these drugs should be tried when used singly. Whether combinations of various SAARDs will be useful still remains to be established, and few double blind randomised studies have been reported. Compared with gold/placebo, gold/hydroxychloroquine produced an increased withdrawal rate owing to rashes, which was balanced by better results for each of 13 clinical, laboratory, and radiological measurements. ${ }^{69}$ Although statistical significance was achieved only for $\mathrm{C}$ reactive protein, an overall advantage of $20-25 \%$ was estimated in favour of the combination. In another study over 48 weeks 335 patients with RA were randomly allocated to receive auranofin, methotrexate, or both. Treatments in the three groups showed a similar efficacy, and although the combination group had few withdrawals for lack of response, there were also more withdrawals for adverse reactions in that group (Williams $\mathrm{H} \mathrm{J}$ et al, paper presented at American College of Rheumatology meeting, November 1991). A recent review concluded that there is no current evidence to favour combination chemotherapy. ${ }^{70}$ In the foumal of Rheumatology opposing leading articles ${ }^{71-73}$ disputed the merits of combination therapy, a dilemma well summarised by Klippel. ${ }^{74}$

Combination therapy may well prove expensive both financially and in terms of side effects. The end effect of the few available options may be similar. It might be that the most appropriate combination has not yet been found, that a second drug should be added to those with a suboptimal response or late relapse, or that the most effective dose of a single drug has not been used. Martin et al found that in those with inadequate response to penicillamine $500 \mathrm{mg}$; increasing the dose was as beneficial as adding hydroxychloroquine, and $50 \%$ of both groups showed marked improvement. ${ }^{75}$ There is no controlled evidence to suggest that combination therapy confers any advantage over a single treatment given in the best possible way. Rheumatologists need to exercise caution lest their desire to help patients overrides scientific and clinical objectivity.
The future?

As noted above, one of the fundamental difficulties with all currently available disease modifying agents in RA is the relatively unselective nature of the effect achieved.- Total white cell count is often decreased, possibly excessively. This is also true of non-specific 'markers' such as immunoglobulins, which fall during SAARD treatment, though hypoglobulinaemia is exceptional. This 'blockbuster' approach seems likely to affect development of immunological agents in RA, as protective as well as destructive modulators will be influenced.

Immunotherapy in RA: will it have a role?

Antibodies directed against crucial components of the early phase of the immune response are an obvious target for immunotherapeutic trials in RA. Again, however, this approach is still relatively unselective and many useful immunological functions may be impaired by these strategies, as well as those concerned with rheumatoid inflammation. Preliminary uncontrolled studies with monoclonal antibody to $\mathrm{CD} 4^{76}$ have shown reduction of CD4+ cells with an inverted CD4/CD8 ratio persisting for three to four weeks. $T$ helper cells remaining after the infusion of the antibody showed a modulation of the CD4 antigen with a strikingly decreased antigen density. These immunological effects were associated with improvements in clinical and laboratory features of RA. It is too early to comment on the potential clinical usefulness of such approaches, however, as this treatment was given for only seven days. Studies of recombinant interferon gamma have shown that similar proportions of patients continue to receive this treatment when compared with SAARDs $-61 \%, 34 \%$, and $26 \%$ respectively continuing with 'sustained benefit' after one, two, and three years. ${ }^{77}$ The need for subcutaneous injections three to seve times a week in patients with possibly impairec and function is likely to prove a drawback. Further studies of inhibitors of interleukin 1 are underway. Manipulation of cytokines or their inhibitors may allow down-regulation of inflammatory and proliferative pathways in $\mathrm{RA}$, thereby reducing production of proteolytic enzymes and prostaglandins by synovial cells. ${ }^{78}$ Even a promising initiation will require refinement before proving useful-this will take time. The slow progress of thymopentin illustrates the difficulties, from an early report in $1980^{79}$ to a Lancet paper in $1985^{80}$ to continued study in $1989 .{ }^{81}$ Some of the problems of intravenous administration, determining the dose, and the weak, short lived effect may apply to other agents in this class, though nasal application might be feasible for some drugs.

\section{Conclusion}

When the molecular basis for initiation and maintenance of RA is known we will be able to offer our patients rational treatment. At present we do not know which specific modes of action of our currently available drugs are relevant, and cannot therefore plan a logical assault upon 
KA. Until this information becomes available, large scale well designed studies will be needed to optimise available drug treatment. Amelioration of symptoms should not be disregarded, but realism in the use of available modulators is vital.

1 Capell H A, Marabani M, Madhok R, Torley H I, Hunter J A. Degree and extent of response to sulphasalazine or penicillamine therapy for rheumatoid arthritis: results from a routine clinical environment over a two year period. $Q \mathcal{J}$ Med 1990; 75: 335-44.

2 Pullar T, Capell H A. Selection of suitable patients for second line therapy in rheumatoid arthritis. Br $\mathcal{F}$ Rheumatol 1986; 25: 276-81.

3 Wolfe F, Hawley D I, Calney M A. Termination of slow acting antirheumatic therapy in rheumatoid arthritis: a 14 year prospective evaluation of 1017 consecutive starts. f Rheumatol 1990; 17: 994-1002.

4 Felson D T, Anderson J J, Meenan R F. The comparative efficacy and toxicity of second line drugs in rheumatoid arthritis. Arthritis Rheum 1990; 33: 1449-61.

5 Singh G, Fries J F, Williams C A, Zatarain E, Spitz P, Bloch D A. Toxicity profiles of disease modifying antirheumatic drugs in rheumatoid arthritis. $\mathcal{F}$ Rheumatol 1991; 18: 2 .

6 Capell H A, Hunter J A, Rennie J A N, Murdoch R M Levamisole-a possible alternative to gold and penicillamine in the longterm treatment of rheumatoid arthritis. f Rheumatol 1981; 8: 730-40.

7 Goldberg A A, Godfrey K E. Fenclofenac. Clin Rheum Di $1980 ; 6$.

8 Anonymous. Benoxaprofen [editorial]. BMF 1982; 285: $459-60$.

9 Egsmose C, Lund B, Anderson R B. Timegadine: more than a non-steroidal for the treatment of rheumatoid arthritis. A controlled, double blind study. Scand $\mathcal{F}$ Rheumatol 1988 17: $103-11$.

10 Larkin J G, Capell H A, Sturrock R D. Seatone in rheumatoid arthritis: a six month placebo controlled study. Ann Rheum Dis 1985; 44: 199-201.

11 Teh L G, Madhok R, Capell H A. Does the addition of ketotifen to non-steroidal anti-inflammatory drugs confer any additional benefit in rheur

12 Brzeski M, Madhok R, Hunter J A, Capell H A. Randomised, double blind, placebo controlled trial of inosine pranobe in rheumatoid arthritis. Ann Rheum Dis 1990; 49: 293-5.

13 Richards I M, Fraser S M, Hunter J A, Capell H A. Comparison of phenytoin and gold as second line drugs in rheumatoid arthritis. Ann Rheum Dis 1987; 46: 667-9.

14 Belch J J F, Madhok R, McArdle B, et al. The effect of increasing fibrinolysis in patients with rheumatoid arthritis a double-blind study of stanozolol. $Q \mathcal{F ~ M e d ~ 1 9 8 6 ; 5 8}$ 19-27.

15 Caruso I, Montrone F, Fumagalli $M$, et al. Rheumatoid knee synovitis successfully treated with intra-articular rifamycin SV. Ann Rheum Dis 1982; 41: 232-6.

16 Gabriel S E, Conn D L, Luthra H. Rifampin therapy in rheumatoid arthritis. $\mathcal{f}$ Rheumatol $1990 ; 17$ : 163-6.

17 Ash G, Baker R, Rajapakse C, Swinson D R. Study of suphamethoxazole in rheumatoid arthritis. $B r \mathscr{f}$ Rheumato 1986; 25: 285-7.

18 Astbury C, Hill J, Bird H A. Cotrimoxazole in rheumatoid arthritis. $B r \mathcal{F}$ Rheumatol 1986; 25 (suppl 2): 46.

19 Breedveld F C, Dijkmans B A C, Mattie H. Minocycline treatment for rheumatoid arthritis: an open dose finding treatment for rheumatoid arthritis:
study. $\mathcal{F}$ Rherumatol $1990 ; 17: 43-6$.

20 Harkness J A L, Griffin A J, Heinrich I, Gibson T, Grahame R. A double-blind comparative study of metronidazole and placebo in rheumatoid arthritis. Rheumatol Rehabil 1982 21: $231-4$

21 Dennison W B, Loeser R F, Turner R A, Johnson J A, Wells H B. A double blind placebo controlled trial of low dose clotrimazole in rheumatoid arthritis. $\mathcal{F}$ Rheumatol 1990; 17: 1003-7.

22 Grimaldi M G. Long term low dose haloperidol treatment in rheumatoid patients: effects on serum sulphydryl levels, technetius index, ESR and clinical response. $\mathrm{Br} \mathcal{f} \mathrm{Clin}$ Pharmacol 1981; 12: 579-81.

23 Martin M F R, Surrall K, McKenna F, Dixon J S, Bird H A Wright V. Captopril: a new treatment for rheumatoid arthritis. Lancet 1984; i: 1325-8.

24 Reidenberg M M, Case D B, Drayer D E, Reis S, Lorenzo B. Development of antinuclear antibody in patients treated with high doses of captopril. Arthritis Rheum 1984; 27: with high

25 Chilles C, Mulheron M, McCrae F M, et al. Concentration and reactivity of the sulphydryl group population on the membrance of intact erythrocytes in patients with rheuma toid arthritis. Ann Rhewm Dis 1990; 49: 668-71.

26 McKenna F, Hickling P, Dixon J, Bird H. Methylcysteine in rheumatoid arthritis. Br I R hetumatol 1986; 25: 132

27 van Rijthoven A W A M, Dijkmans B A C. The H S G, et al. Cyclosporin treatment for rheumatoid arthritis: a placebo controlled, double blind multicentre study. Ann Rheum Dis 1986; 45: 726-31.

28 Weinblatt M E, Coblyn J S, Fraser P A, et al. Cyclosporin A treatment of refractory rheumatoid arthritis. Arthritis Rhewon 1987; 30: 11-7.

29 Tugwell P, Bombardier C, Gent M, et al. Low dose cyclosporin versus placebo in patients with rheumatoid arthritis. Lancet 1990; 335: 1051-5.

30 Moran M, Mozes M F, Maddux M S, et al. Prevention of acute graft rejection by the prostaglandin E1 analogue misoprostol in renal transplant recipients treated with cyclosporin and prednisone. $N$ Engl $\mathcal{J}$ Med 1990; 322: cyclosporin

31 Porter D, Madhok R, Hunter J, Capell H. A prospective trial comparing the use of sulphasalazine and auranofin as second line agents in patients with rheumatoid arthritis. Ann Rheum Dis. In press.

32 Weinblatt M E, Kaplan H, Germain B F, et al. Low-dose methotrexate compared with auranofin in adult rheumatoid arthritis. Arthritis Rheum 1990; 33: 330-8.

33 Carette S, Calin A, McCafferty J P, Wallin B A, and the Auranofin Cooperating Group. A' double-blind placebocontrolled study of auranofin in patients with psoriatic arthritis. Arthritis Rheum 1989; 32: 158-65.

34 Palit J, Hill J, Capell H A, et al. A multicentre double-blind comparison of auranofin, intramuscular gold thiomalate and placebo in patients with psoriatic arthritis. $\mathrm{Br} \mathcal{F}$ Rheumatol 1990; 29: 000-000.

35 Pullar T, Hunter J, Capell H A. Sulphasalazine in rheumatoid arthritis: a double blind comparison of sulphasalazine with placebo and sodium aurothiomalate. $B M \mathcal{F} 1983 ; 287$ : $1102-4$.

36 McConkey B. Sulphasalazine and ankylosing spondylitis. $\mathrm{Br}$ f Rheumatol 1990; 29: 2-3.

37 Farr M, Kitas G D, Waterhouse L, Jubb R, Felix-Davies D, Bacon P A. Sulphasalazine in psoriatic arthritis: a doubleblind placebo controlled study. Br $\mathcal{F}$ Rheumatol 1990; 29: 46-9.

38 Trnavsky K, Peliskova Z, Vacha J: Sulphasalazine in the treatment of reactive arthritis. Scand $\mathcal{F}$ Rheumatol $1988 ; 17$ (suppl 67): 76-9.

39 Willkens R F. Resolve: methotrexate is the drug of choice after NSAIDs in rheumatoid arthritis. Semin Arthritis Rheum 1990; 20: 76-80.

40 Furst D E. Proposition: methotrexate should not be the first second-line agent to be used in rheumatoid arthritis if NSAIDs fail. Semin Arthritis Rheum 1990; 20: 69-75.

41 Kremer J M, Lee J K. The safety and efficacy of the use of methotrexate in long-term therapy for rheumatoid arthritis. Arthritis Rheum 1986; 29: 822-31.

42 Willkens R F, Leonard P A, Clegg D O, et al. Liver histology in patients receiving low dose pulse methotrexate for the treatment of rheumatoid arthritis. Ann Rheum Dis 1990; 49: treatment

43 Pullar T, Capell H A. A rheumatological dilemma: Is it possible to alter the course of rheumatoid arthritis? Can we answer the question? Ann Rheum Dis 1985; 44: 134-40.

44 Williams H, Ward J R, Dahl S L, et al. A controlled trial comparing sulphasalazine, gold sodium aurothiomalate, and placebo in rheumatoid arthritis. Arthritis Rheum 1988; 31: 702-13.

45 Situnyake R D, Grindulus K A, McConkey B. Long term treatment of RA with sulphasalazine, gold or penicillamine: a comparison using life-table methods. Ann Rheum Dis 1987; 46: 177-83.

46 Bax D E, Amos R S. Sulphasalazine in rheumatoid arthritis: desensitising the patient with a skin rash. Ann Rheum Dis 1986; 45: $139-40$.

47 Morgan S L, Baggott J E, Vaughn W H, et al. The effect of folic acid supplementation on the toxicity of low dose methotrexate in patients with rheumatoid arthritis. Arthritis Rheum 1990; 33: 9-18.

48 Hansen T M, Kryger P, Elling H, et al. Double-blind placebo controlled trial of pulse treatment with methylprednisolone combined with disease modifying drugs in rheumatoid arthritis. $B M \mathcal{F}$ 1990; 301: 268-70.

49 Steven M M, Hunter J A, Murdoch R M, et al. Does the order of second-line treatment in rheumatoid arthritis order of second-line treatment
matter? $B M \mathcal{J} 1982 ; 284: 79-81$.

50 Dahl S L, Coleman M L, Williams H J, et al. Lack of correlation between blood gold concentrations and clinical response in patients with definite or classical rheumatoid arthritis receiving auranofin or gold sodium aurothiomalate. Arthritis Rheum 1985; 28: 1211-8.

51 Pullar T, Hunter J A, Capell H A. Sulphasalazine in the treatment of rheumatoid arthritis: relationship of dose and serum levels to efficacy. $\operatorname{Br} \mathcal{F}$ Rheumatol 1985; 24: 269-76.

52 Graham G G, Haavisto T M, McNaught R J, Browne C D, Champion $G \mathrm{D}$. The effect of smoking on the distribution of gold in blood. F Rheumatol 1982; 9: 527-31.

53 Pullar T, Hunter J A, Capell H A. Effect of acetylator phenotype on efficacy and toxicity of sulphasalazine in rheumatoid arthritis. Ann Rheum Dis 1985; 44: 831-7.

54 Dahlqvist S R, Mjorndal T. Acetylator phenotypes in reumatoid arthritis patients with or without adverse drug reactions to sodium aurothiomalate

55 Wooley P H, Griffin J, Panayi G S, Batchelor J R, Welsh K I, Gibson T J. HLA-DR antigens and toxic reaction to sodium aurothiomalate and d-penicillamine in patients with rheumatoid arthritis. $N$ Engl f Med 1980; 303: 300-2.

56 Madhok R, Zoma A, Torley H I, Capell H A, Waring R, Hunter J A. The relationship of sulphoxidation status to efficacy and toxicity of penicillamine in the treatment of rheumatoid arthritis. Arthritis Rheum 1990; 33: 544-7.

57 Adachi J D, Bensen W G, Kassam Y, et al. Gold induced thrombocytopenia: 12 cases and a review of the literature. Semin Arthritis Rheum 1987; 16: 287-93.

58 Madhok R, Pullar T, Capell H A, Dawood F, Sturrock R D, Dick H M. Chrysotherapy and thrombocytopenia. Ann Rheum Dis 1985; 44: 589-91. 
59 Wijnands M J, Van Riel P L, Gribnau F W, van de Putte L B. Risk factors of second line antirheumatic drugs in rheumatoid arthritis. Semin Arthritis Rheum 1990; 19: 337-52.

60 Pullar T, Peaker S, Martin M F R, Bird H A, Feely M P. The use of a pharmacological indicator to investigate compliance in patients with a poor response to antirheumatic therapy. Br F Rheumatol 1988; 27: 381-4.

61 Brower A C. Use of the radiograph to measure the course of rheumatoid arthritis. Arthritis Rheum 1990; 33: 316-24.

62 İannuzzi M D, Dawson $\bar{N}$, Zein $\bar{N}$, Kushner I. Does drug therapy slow radiographic deterioration in rheumatoid arthritis? $N$ Engl $\mathcal{F}$ Med 1983; 307: 1023-8.

$6 \overline{3}$ Cooperating clinics committee of the Āmerican Rheumatology Association. A controlled trial of cyclophosphamide in rheumatoid arthritis. N Engl f Med 1970; 283: 883-9.

64 Van der Heijde $\bar{D} \bar{M}$, Van Riel $\overline{\mathbf{P}} \overline{\mathbf{L}}$, Nuver-Zwart i H, Gibnau $F$ W, van de Putte $\mathbf{L}$ B A. Effects of hydroxychloroquine and sulphasalazine on progression of join damage in rheumatoid arthritis. Lancet 1989; 335: 1036-8.

$6 \overline{5}$ Vañ der Heijé D M F $\bar{M}$, Van Riē P $\bar{L} \bar{C} \bar{M}$, Nuver-Zwart I H, van de Putte L B A. Sulphasalazine versus hydroxychloroquine in rheumatoid arthritis: 3 year follow up. Lancet 1990; 335: 539 .

66 Pullar T, Hunter J A, Capell H A. Effects of sulphasalazine on the radiological progression of rheumatoid arthritis. Ann Rheum Dis 1987; 46: 398-402.

67 Borg G, Allander E, Lund B, et al. Auranofin improves outcome in early rheumatoid arthritis. Results from a two year, double-blind, placebo controlled study. $f$ Rheumatol year, double-blind,
1988; 15: 1747-54.

68 Scott D L, Dawes P T, Fowler P D, Grindulis K A, Shadforth M, Bacon P A. Antirheumatic drugs and join damage in rheumatoid arthritis. $Q \mathcal{Y} M e d 1985 ; 54: 49-59$.

69 Scott D L, Dawes P T, Tunn E, et al. Combination therapy with gold and hydroxychloroquine in rheumatoid arthritis: a prospective, randomised, placebo controlled study. $\mathrm{Br} \mathcal{J}$
Rheumatol 1989; 28: 128-33.
70 Paulus H E. The use of combinations of disease-modifying antirheumatic agents in rheumatoid arthritis. Arthritis Rheum 1990; 33: 113-20.

71 Bensen $W$ G, Bensen $W$, Adachi J D, Tugwell $P$ X Remodeling the pyramid: the therapeutic Remodeling the pyramid: the therapeutic target
toid arthritis. $\mathcal{F}$ Rheumatol 1990 ; 17: $987-9$.

72 Wilske $K$ R, Healey L A. Remodeling the pyramid-a concept whose time has come. $\mathcal{J}$ Rheumatol 1989; 16: 565-7.

73 McCarty D J. Suppress rheumatoid inflammation early and leave the pyramid to the Egyptians. $\mathcal{O}$ Rheumatol 1990; 17: $1115-8$.

74 Klippel J H. Winning the battle, losing the war? Another editorial about rheumatoid arthritis. $\mathcal{F}$ Rheumatol 1990; 17: 1118-22.

75 Martin M, Sitton N, Dixon J, Hickling P, Golding J, Wright V. Penicillamine failures- what can be done? Ann Rheum Dis 1982; 41: 631-2.

76 Burmester $G R$, Horneff $G$, Emmrich $E$, Kalden J $R$ Immunomodulatory treatment of rheumatoid arthritis with anti-CD4 (anti-helper T cell) monoclonal antibody. Arthritis Rheum 1990; 33 (suppl): S25.

77 Cannon G W, Kennedy S M, Emkey R D, et al. Prospective three year follow up of recombinant interferon-gamma in rheumatoid arthritis. Arthritis Rheum 1990; 33 (suppl): S25.

78 Harris E D. Rheumatoid arthritis. Pathophysiology and implications for therapy. $N$ Engl $\mathcal{f}$ Med 1990; 322: 1277-89.

79 Horwitz D A, Glynn M J, Barada F A, et al. Effects of thymopentin 32-36 (TP-5) in rheumatoid arthritis-a
preliminary report. In: Krakauer $R$ S, Cathcart M K, eds. Immunoregulation and autoimmunity. Amsterdam: Elsevier, 1980: 231 .

80 Malaise M G, Hauwaert C, Franchimont $P$, et al. Treatment of active rheumatoid arthritis with slow IV injections of thymopentin. Lancet 1985; i: 832-6.

81 Kantharia B K, Goulding N J, Hall N D, et al. Thymopentin (TP-5) in the treatment of rheumatoid arthritis. Br $\mathcal{J}$ Rheumatol 1989; 28: 118-23. 